\title{
Состоялась ли «Премьера»?
}

\section{Was There a "Premiere"?}

\author{
Инна Калита \\ (Усти-над-Лабем, Чешская Республика)
}

\section{Абстракт:}

Статья посвящена новой книге А. Горвата «Премьера» (2018). Анализ основан на ее сравнении с первой книгой, которая в 2016 году стала в Беларуси настоящей сенсацией и принесла популярность неизвестному автору. Рассмотрены отдельные составляющие, отличающие «Премьеру» от «Радио 〈Прудок»». Критическому пересмотру подвергается роль и объем трасянки в художественном тексте. Образность, лиричность и лаконизм изложения, более качественно представленные в первой книге, присутствуют и в «Премьере», однако «неуверенность» автора, который сам превратился в персонажа, не позволяет реализоваться этим качествам в полной мере.

\section{Ключевые слова:}

современная беларусская литература; «Премьера»; Андрей Горват; авторский стиль; трасянка; стилистика текста; автор-персонаж

\section{Abstract:}

This article is dedicated to A. Horvat's new book "Premiere" (2018). The analysis is based on comparison with his first book, which became a real sensation in Belarus in 2016 and also brought popularity to the previously unknown author. Individual parts that differentiate "Premiere" from "Radio 'Prudok"” are analysed. Role and quantity of trasyanka in this artistic text is critically reviewed. Characters, lyricism and laconism of the work that were better presented in the first book can be also found in "Premiere", but insecurity of the author, that has himself became a character, does not allow him to fully implement those assets.

\section{Key words:}

contemporary Belarusian literature; "Premiere"; Andrej Horvat; author's style; trasjanka; stylistic features of a literary text; author/character 


\section{1 Введение}

Литературным событием 2016 года в Беларуси стала книга А. Горвата «Радио 〈Прудок〉», которую сразу назвали новым словом в современной беларусской литературе. Дневниковые записи в социальной сети Фэйсбук сложились в книгу и благодаря краудфандинговой платформе вышли в бумажном формате. Книга была ожидаемой - любители беларусского слова, поддержавшие издание, ожидали книгу с нетерпением. Неожиданностью оказалась вторая книга Горвата, вышедшая в 2018 году. «Премьера» (бел. «Прэм’ера») появилась в продаже без всякой предварительной рекламы и какой-либо информации. Имя автора, стремительно завоевавшего беларусскую литературную сцену, стало узнаваемым после первой книги и поставленного по ней спектакля, поэтому такой «необъявленный» выход в свет его второй книги стал для читателей сюрпризом.

Первое, что обращает на себя внимание уже на обложке - имя автора. В первой книге использован вариант имени Андрусь, в «Премьере» - Андрей. В беларусской традиции варианты типа Андрусь, Адась и т. д. используются чаще в обращениях к подросткам и молодым людям. Вероятно, автор таким образом подчеркивает переход к какому-то новому этапу своей жизни определенной ступеньке взросления. И сам текст новой книги искуственно «выталкивается» автором на новую жизненную ступень. Но в отличие от первой книги, преподнесенный «новый формат» не производит впечатления абсолютной естественности.

Задачей данной статьи является рассмотрение отдельных тенденций, отличающих «Премьеру» от «Радио 〈Прудок〉». Обратим внимание на трасянку неотъемлемый элемент авторского стиля, и в этой связи объясним, почему страдает стилистика горватовского текста.

\section{2 Диссонансы в восприятии «Премьеры»}

Название книги «Премьера» ассоциативно и тематически связывает текст с постановкой спектакля по первой книге автора, описание подготовки и репетиции которого непосредственно вписаны в текст книги. Автор становится свидетелем и участником процесса, в котором его текст перерастает в иной формат, он наблюдает, как оживают описанные им герои, и как деревенские образы в исполнении актеров наполняются новым содержанием и практически переходят в иную плоскость существования. Иначе говоря, «Премьера» представляет процесс переформатирования самого автора и созданных им в «Радио 〈Прудок〉» образов. Однако мы рассматриваем художественное произведение, подразумевая наличие в нем соответствующих данному стилю категорий 
и средств, обращённых к читателю. Потому возникает закономерный вопрос в каком объеме и формате может быть отражен процесс переформатирования героев одной книги на страницах другой книги?

Если предположить, что автор задумывал «Премьеру» как продолжение «Радио 〈Прудок»», полноценного продолжения, на наш взгляд, не получилось, также как не получилось и нового самостоятельного полноценного произведения. Автор не вырос, не набрался опыта.

Однако мнения критиков относительно «Премьеры» диаметрально расходятся. В. Мартинович отстаивает мысль, что «Премьера» - не продолжение «Радио...», а самостоятельная повесть, написанная на другом уровне. В противоположность другим он считает «Премьеру» более удачной, чем «Радио 〈Прудок〉». «Радио...» возвращало литературу в русло беларусской деревни. Хата, земля, печка, коза. Нищета и крестьяне, которых хочется пожалеть. К тому же «Радио...» было не только литературным произведением. Значительная часть его успеха была связана с выходом автора из комфорта повседневности, его углублением в деревенскую трясину. О Горвате сначала говорили, что он уехал в Прудок и живет там с козой, и только потом - что он писатель ${ }^{1}$.

Рецензия «Фігаро тут, Фігаро там. Колькі словаў аб прэм'еры горватаўскай 〈Прэм'еры〉», помещенная на Белсат, неоднозначна. В ней говорится, что взросление героя очевидно - он уже более чем романтик, который поехал вместе с котом отстраивать дом деда. Далее следует - Горват «хотел копнуть глубже, но в последний момент бросил лопату и пошел в магазин за хлебом, потеряв к копанию глубин всякий интерес. Ведь «Премьера» в определенных моментах выглядит как черновик художника: несколько штрихов здесь, эскиз там. Здесь - зарисовка из берлинского бара, там - из испанской деревни, но ни одна линия не доведена до конца. А может так и надо? А может, ничего и не должно быть понятно?» ${ }^{2}$.

М. Жбанков отмечает, что в «Премьере» видно, как автор старается.

«И хочется, чтобы он старался немного меньше. Чтобы снова позволил себе свободу: безответственность, мечтательность, разорванность чувств и необязательность выводов, акварельность мыслей с яблоком в дырявом кармане. Подобные моменты, впрочем, есть и в новой книжке. Но их непростительно мало.

1 MARCİNOVİČ, V.: Kol'kì slovaŭ pra «Prèm’jeru» Horvata. (11. 2. 2019). <https://budzma.by/news/ marcinovich-horvat.html>. [online]. [cit. 1. 5. 2019]. Перевод И. К.

2 Fìgaro tut, Fìgaro tam. Kol'kì slovaŭ ab prèm'jery gorvataŭskaj «Prèm'jery». (28. 12. 2018). <https:// belsat.eu/news/figaro-tut-figaro-tam-kolki-slovau-ab-prem-ery-gorvatauskaj-prem-ery/>. [online]. [cit. 1. 5. 2019]. Перевод И. К. 
Вот вам и мизансцена: одинокий автор посреди пустоты. Светит лишь экран лаптопа. Остальное - шорох слов, хоровод образов» ${ }^{3}$.

Вторая книга, на наш взгляд, выдвигает на первый план театральную сцену. В книге исчезают живые чувственные образы - они превращаюся в марионеток, которых дергают за нити - им всем предписаны роли. Образ автора, слившись с персонажем, казалось бы, имеет больше свободы, нежели остальные, но в этой новой ситуации он не знает что делать. Автор-персонаж теряется в догадках как себя вести дальше, каким быть, он не тождественен ни реальному автору, ни персонажу, родившемуся в первой книге. Возможно, лирический герой был бы рад впустить читателя в свое внутреннее пространство - так, как это получилось в «Радио 〈Прудок»», но это пространство по какой-то причине «сузилось», искренность «скукожилась» под воздействием ощущения себя на «театральной сцене».

Реминисцентная связь с первой книгой очевидна, однако исповедальность, благодаря которой «Радио 〈Прудок»» привлекло внимание большого количества читателей, в «Премьере» ушла в другое русло - исповедальные мотивы затмила описательность, хаотичность ощущений и событий.

\section{3 Театр превыше всего, или одиночество в толпе}

В книге «Радио 〈Прудок»» автор отсутствовал, читатель ощущал присутствие лирического героя. В «Премьере» автор есть, есть самоощущение автора книги Автором. Причем автора «много», создается ощущение доминантности авторского образа, который в принципе является малодеятельным, и даже неуверенным наблюдателем, даже при том, что происходит раздвоение авторского образа - параллельно идут автор и персонаж. В целом во второй книге меньше чувственности, меньше «внутреннего», сокровенного, меньше общения с жителями Прудка, и больший крен в значимость авторского образа. С одной стороны, подчеркивается скромность автора (на репетиции спектакля хотел занять место в самом углу), но с другой - репетиции продолжаются и описания присутствия автора становятся затянутыми местами текста. Возникает ощущение несбывшегося ожидания, которое можно проиллюстрировать выдержкой из текста книги (Вечарэла. 3 неба мусілі падаць знічкі у вядро ля студні і назаўжды станавіцца пажоўкльм лісцем. Але нічога такога не адбывалася. Неба было зацягнута камарамі. ${ }^{4}$ ). На одной из репетиций автор заменяет отсутствующего актера (Яго рэпліка прагучала неяк па-дурному,

3 ŽBANKOŬ, M.: Druhi Horvat: sèppuku post-litaratury. (23. 1. 2019). <https://bookster.by/reviews/ druhi-horvat-seppuku-post-litaratury>. [online]. [cit. 1. 5. 2019]. Перевод И. К.

4 HORVAT, A.: Prèm'jera. Mìnsk: Medysont, 2018, s. 33. 
несур'ёзна. Аўтар адчуў, што мэтры скрывіліся. Адзін нават чыхнуў.). Описание других репетиций совмещает саму репетицию и реминисцентные отблески жизненных ощущений автора. За счет такого подхода книга становится более «текстом для себя - автора», нежели текстом, в котором читателю есть место для «включения» в событийное полотно. По этой причине «Премьера» проигрывает и уступает книге «Радио 〈Прудок〉», которую в философском ключе можно обозначить как поиски равновесия.

Формулируя понятие интериоризации игры актера на сцене, М. Мамардашвили объяснял: «вы увидите те состояния мысли и понимания, и чувства, которые сущцествуют на сцене только в момент реализации, то есть тогда, когда. Вот оно реализовалось, стало на ноги, кристаллизовалось! И в этот момент (обставленный неизобразительными шумами, неизобразительными позами, криками, неизобразительной музыкой и т.д.) реализация должна просто быть как бы алхимическим тиглем, чтобы внутри этого тигля выпала, как золото выпадает в осадок, полнота человеческого акта мысли, полнота понимания самого себя или полнота человеческого существа».

К кристаллизации, на наш взгляд, в «Премьере» не дошло, «центральные точки» истинных впечатлений переместились в кривой дискурс.

«Дискурс страстного свидания с самим собой - наше впечатление в нашей проработке [...] начинает пробегать свой кривой путь, все более отдаляющий его от того, что было на самом деле. То есть оно прорастает в мирь, а они как раз этой отдаляющейся кривой выстраиваются. И наше существо, вместо того, чтобы удержаться и остаться живым на этой кривой, все время умирает в тех мирах, в которье эта кривая его заводит» ${ }^{5}$.

«Премьера» не дает образа полноты мысли, полноты понимания самого себя, но также не дает и ощущения, что автор стремится к этому пониманию. На это указывает кардинальное изменение взгляда автора на свою роль в парадигме мужчина - женщина. Если в первой книге лирический герой мечтает о семье, то во второй он напрочь отказывается от этой идеи (отвык я от всего этого). И даже в пьяном состоянии он ведет внутренний диалог и радуется тому, что никто не увидит его таким пьяным. Он думает - хорошо возвращаться домой, когда там никто не ждет. Ремарк бы одобрил этот мой тезис. В этом контексте произведения А.Горвата, которые в принципе тяжело отнести к постмодернизму, вписываются в эту парадигму по признаку образования «пустоты».

5 MAMARDAŠVILI, M. K.: Psichologičeskaja topologija puti. Lekcija 18. (17. 11. 1984)<http://www. magister.konvent.ru/lib/ELIB/mkmamooo/mkmto18.htm>. [online]. [cit. 1. 5. 2019]. 
Как отмечает И.Поспишил, этот период комы постмодерна страдает от избытка общения, которое часто заканчивается в пустоте, в «одиночестве среди людей» ${ }^{6}$.

Название «Премьера» вызывает естественную ассоциацию с театром, а значит и сценой. Именно сцена, сценичность - театральность в целом заполняют страницы книги. Но поведение автора-персонажа в этом спектакле неуверенное, угловатое, оно «подстраивается» под театр, под роль - то есть создание массовости, многолюдности коммуникации. И в результате возникает аналогия с коммуникацией в социальных сетях - все представлены одновременно в одном виртуальном пространстве, многие рады показать свои новые «костюмы», «игрушки», социальные и семейные «роли» - то есть «театр» превалирует над ходом жизненных событий, опережает или замещает глубокие чувства, на первый план выходит роль и ролеобразующие «доспехи» и «кулисы». Стремление ухода от одиночества ведет к «одиночеству в толпе».

И даже Париж, в действительности вдохновивший А. Горвата - автора, со страниц книги не производит такой эмоциональной встряски. Хотя стоит отдать должное автору - несмотря на любование городом, он отражает катастрофические тенденции современной цивилизации, касающиеся отношения к человеку.

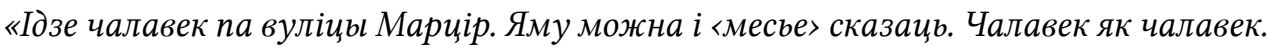
Нармальны. Потым ён спьняециа ля брыля, пад якім ляжыць матрац. Гэта яго дом. Чалавек прыйшоў дадому. Яго на матрацы чакае жонка. Чалавек здымае касиюм, акуратна вешае яго на плечыкі і сядае вячэраць. Такія матрацы паусюль. Днём яны стаяць, прыхіленыя да сцен, а ӱвечары парыжскія вуліщы ператварающца у плацкартныя вагоны» ${ }^{7}$.

\section{4 Язык Андруся и язык Андрея}

Кроме образных и содержательных отличий двух книг, разделенных по времени написания небольшим отрезком времени, привлекает внимание иной подход к использованию языковых средств и внимания к самому языку.

В первой книге находим удачные наблюдения над живой беларусской речью. Автор обращает внимание на специфические особенности разговорно-диалектных слов и конструкций. Язык первой книги А. Горвата «органичен (не исключая

6 POSPÍŠIL, I.: Disperze a míjení: literatura a její výzkum na prahu nové éry. Slavica litteraria, 2009, № 1, s. 26. Перевод И. К.

7 HORVAT, A.: Prèm'jera. Mìnsk: Medysont, 2018, s. 175. 
сниженные единицы), автор не приспосабливает его к городской или деревенской среде, не подчиняет условиям ХХІ века» ${ }^{8}$.

Вторая книга в языковом плане отличается определенной небрежностью. Одним из основных стилистических средств Горвата является трасянка. Трасянка как средство создания образа и стилистических эффектов далеко не новое, Горват не является его первооткрывателем.

Трасянка, хотя и употребляется на бытовом уровне, выходит далеко за его рамки (напр., устный официально-деловой стиль в первый срок президента А. Лукашенко). Употребление элементов трасянки (транскода) часто встречается в текстах популярных песен и публицистике - от одного слова, словосочетания, до вставки одного или нескольких предложений в русский текст, либо употребления в русском тексте беларусских паремий. Эта тенденция в беларусской русскоязычной прессе наблюдается давно» ${ }^{9}$.

Во второй книге диалоги переполнены трасянкой и читатель вынужден в ней «погрязнуть». Образ трасянковой коммуникации дополняет раздвоившийся образ автора: автор-персонаж в авторской позиции использует литературный язык и иногда соскальзывает на трасянку, а автор в роли персонажа говорит на трасянке. Конечно же, на этом «языке» говорят все герои. В «Радио 〈Прудок»» ярким лейтмотивом звучит уважение к языку, выделение и осознание отличия диалектных особенностей Гомельщины как чего-то более близкого и родного (также как в традиции И.Мележа). Автор второй книги на уровне стилистическом значительно проигрывает Андрусю Горвату. Хотя, безусловно, на подсознательном уровне он отражает реальную проблему современной Беларуси, касающуюся состояния национального языка, которое с каждым годом усугубляется. Однако отсутствие национальной и языковой политики не должно таким образом отражаться на качастве языка художественной литературы, потому что именно язык писателя должен служить эталоном литературной нормы. При этом мы не выступаем против использования трасянки, не ратуем за удаление ее из литературных и других художественных текстов. Быть писателем большая ответственность, кроме того быть писателем - значит быть хорошим стилистом.

8 KALITA, I.: Vozvrat $k$ «kornjam»-doroga v buduščeje. «Radio 〈Prudok»»-novoje slovo v sovremennoj belarusskoj literature. Opera Slavica, 2018, № 3, s. 42-43.

9 KALITA, I. V.: Sovremennaja Belarus': jazyki i nacional'naja identičnost'. Ústí nad Labem: PF UJEP, 2010, S. 177 . 


\section{5 Выводы}

Подводя итог, хочется привести мысли, высказанные беларусскими критиками, с которыми невозможно не согласится. Прежде всего это высказывание М. Жбанкова, определяющее разницу между первой и второй книгой:

Горвату тяжело: Андрусик ужо закончился, Андрей еще не сложился.

Литературный обозреватель Андрей Адамович после прочтения «Премьеры» не советовал повторять этот опыт тем, кто не хочет разочароваться. Среди его «спойлеров» назовем следующее: первые страницы книги создают впечатление, что автор решил почти слово в слово переписать «Радио 〈Прудок〉», немного перасыпав старые шутки метарефлексиями; словно услышав обвинения критиков, лирический герой сообщает нам, что он решил добавить в текст Олю - так сказать, оживить линию любви. Но проблема в том, что Оля так и остается картонкой - элементом декорации. Она не становится живым человеком, ей невозможно сопереживать ${ }^{10}$. Вывод А. Адамовича заключается в том, что «Премьера» - произведение новичка, ученическая зарисовка, она на голову ниже книги «Радио 〈Прудок〉». Именно поэтому в названии его статьи звучит фраза - почему Горват издал первую книгу позже второй.

Тот же А.Адамович замечает, что есть в беларусской литературе произведения, основанные на любви к Родине, есть произведения, вызванные к жизни любовью к женщине, самому себе или даже неутолимым желанием випить. К сказанному стоит добавить, что «Премьера», хотя и затрагивает все вышеперечисленное, вряд ли хотя бы один из названных пунктов можно рассматривать как главный импульс. Более того, ощущуается именно большая «нехватка» всего перечисленного.

- Нехватка Родины как культурного пространства (вероятно поэтому возникает образ советской Родины с ее первостепенным атрибутом: герои и автор/персонаж озабочены исчезновением с площади памятника Ленину). Советская атрибутика, ставшая привычной за долгие годы, приравнивается к привычной «кулисе» и замещает «пустоту», т. к. национальные маркеры архитектуры и культуры в целом были стерты с лица земли во время Великой отечественной войны. А новое рождается медленно... В тексте книги «нехватка культурного пространства» отражается и в форме культурных и приобретенных стереотипов, вложенных системой образования: «Мяне навучылі у школе, што адлегласиь да Нью-Йорка - сем тысяч кіламетраў. Так мусіщь быць заўсёды. Гэта канстанта. Тэмпература цела здаровага чалавека -

10 ADAMOVİČ, A.: Njaskončanaja p’jesa dlja mechaničnaj kazy: čamu Horvat vydaŭ peršuju knihu paznej za druhuju. (26. 12. 2018). <https://budzma.by/news/horvat-premiera.html>. [online]. [cit. 1. 5. 2019]. 
трыццаць шэсць і шэсць. Кастрычніцкая рэвалющыя адбылася сёмага лістапада. На плошчы стаіць Ленін. Восьмага сакавіка трэба дарыць маме цюльпаны. Гэта рэальнасцьљ» ${ }^{11}$.

- Отсутствие любви («рабочий» образ Оли не выписан четко, он остается образом театральным, марионеточным, «вписанным» в текст как бы по необходимости. Оля не превращается в любимую, не превращается в музу. Герой боится любви).

- Любви к самому себе - малая толика, скорее даже не к себе как человеку а к себе как автору-персонажу. Лирический герой сделал первый взрослый шаг - уехал в деревню и приобрел новый духовный опыт (это произошло в первой книге). Лирический герой, переселившийся во вторую книгу статичен, он делает шаги к познанию внешнего мира (поездки за границу), но приобретенный опыт во второй книге не вылился во что-то осмысленное. В мыслях и поведении персонажа царит хаос.

- Тема «выпить» присутствует в книге, она связана с мыслями об одиночестве. Алкоголь не перерастает во что-то большее и не является поводом «излить» душу.

Наконец обратимся к высказыванию А. Горвата о его первой книге, которая определяет «водораздел» между Андрусем и Андреем.

«Книга писалась через образ, не исключающий театрализованность. Этот образ выциел из меня. Но не надо его полностью со мной отождествлять. Когда люди лезут за предель этого образа, я не пускаю их в мое пространство. Я придумал этого персонажа не целенаправленно. Это произошло само собой. Персонаж отличается тем, что он более чем я реализован, более весел, открыт и искренен» ${ }^{12}$.

Лирический герой «Радио 〈Прудок»» характеризуется остроумностью, юмористичностью, внутренней полнотой, открытостью миру, своеобразным умиротворением и стремлением к гармонии с миром внутренним и внешним, с корнями и кроной - предками и космосом. «Премьера» отражает определенную зацикленность, депрессивность, психологическое отгораживание от мира.

Безусловно, в книге есть удачные моменты. К достоинствам Горвата относится его умение показать бытовые моменты без излишней детализации и описательности, связать реминисцентные нити без «обрезания» долгих концов. Лаконизм изложения, более качественно представленный в первой

11 HORVAT, A.: Prèm'jera. Mìnsk: Medysont, 2018, s. 152.

12 HORVAT, A.: «Adzinota - hèta moj vybar». Andrus' Horvat pra Paryž, adčuvan'ne domu i «Dalinu anelaŭ». (6. 2. 2018). URL: <https://www.svaboda.org/a/29021079.html>. [online]. [cit. 1. 5. 2019]. 
книге, присутствует и в «Премьере», однако неуверенность автора-персонажа не позволяет реализоваться этому качеству в полной мере.

\section{Литература:}

ADAMOVİČ, A.: Njaskončanaja p’jesa dlja mechaničnaj kazy: čamu Horvat vydaŭ peršuju knihu paznej za druhuju. (26. 12. 2018). <https://budzma.by/news/horvatpremiera.html>. [online]. [cit. 1. 5. 2019].

Fìgaro tut, Fìgaro tam. Kol'kì slovaŭ ab prèm'jery gorvataŭskaj «Prèm'jery». (28. 12. 2018). $<$ https://belsat.eu/news/figaro-tut-figaro-tam-kolki-slovau-ab-prem-ery-gorvatau skaj-prem-ery/>. [online]. [cit. 1. 5. 2019].

HORVAT, A.: «Adzinota - hèta moj vybar». Andrus' Horvat pra Paryž, adčuvan'ne domu $i$ «Dalinu anelaŭ». (6. 2. 2018). <https://www.svaboda.org/a/29021079.html>. [online]. [cit. 1. 5. 2019].

HORVAT, A.: Prèm'jera. Mìnsk: Medysont, 2018. ISBN 978-985-7199-56-3.

KALITA, I. V.: Sovremennaja Belarus': jazyki i nacional'naja identičnost'. Ústí nad Labem: PF UJEP, 2010. ISBN 978-80-7414-324-3.

KALITA, I.: Vozvrat $k$ «kornjam» - doroga v buduščeje. «Radio 〈Prudok>» - novoje slovo $v$ sovremennoj belarusskoj literature. Opera Slavica, 2018, № 3, s. 33-44. ISSN 1211-7676.

MAMARDAŠVILI, M. K.: Psichologičeskaja topologija puti. Lekcija 18. (17. 11. 1984) <http://www.magister.konvent.ru/lib/ELIB/mkmamooo/mkmto18.htm>. [online]. [cit. 1. 5. 2019].

MARCÌNOVİČ, V.: Kol’kì slovaŭ pra «Prèm’jeru» Horvata. (11. 2. 2019). <https://budzma. by/news/marcinovich-horvat.html >. [online]. [cit. 1. 5. 2019].

POSPÍŠIL, I.: Disperze a míjení: literatura a její výzkum na prahu nové éry. Slavica litteraria, 2009, № 1, s. 25-39. ISSN 1212-1509.

ŽBANKOŬ, M.: Druhi Horvat: sèppuku post-litaratury. (23. 1. 2019). <https://bookster. by/reviews/druhi-horvat-seppuku-post-litaratury>. [online]. [cit. 1. 5. 2019].

\section{About the author}

\section{Inna Kalita}

Jan Evangelista Purkyne University in Ústí nad Labem, Faculty of Education, Department of Bohemistic Studies, Ústí nad Labem, Czech Republic 